\title{
The Impacts of Machine Learning in Financial Crisis Prediction
}

\author{
Siddhartha Vadlamudi \\ Software Engineer II, Xandr, AT\&T Services Inc., New York, USA \\ E-mail for correspondence: vadlamudisiddhartha@gmail.com
}

https://doi.org/10.18034/abr.v10i3.528

\begin{abstract}
The most complicated and expected issue to be handled in corporate firms, small-scale businesses, and investors' even governments are financial crisis prediction. To this effect, it was of interest to us to investigate the current impact of the newly employed technique that is machine learning (ML) to handle this menace in all spheres of business both private and public. The study uses systematic literature assessment to study the impact of ML in financial crisis prediction. From the selected works of literature, we have been able to establish the important role play by this method in the prediction of bankruptcy and creditworthiness that was not handled appropriately by others method. Also, machine learning helps in data handling, data privacy, and confidentiality. This study presents a leading approach to achieving financial growth and plasticity in corporate organizations. We, therefore, recommend a real-time study to investigate the impact of ML in FCP.
\end{abstract}

Key words: Machine learning, financial crisis prediction, bankruptcy, creditworthiness

\section{INTRODUCTION}

Financial communities, lending organizations, and management organizations are craving to construct an instrument or a theoretical framework that will help them examine the probability of up-to-date avoidance; that is to forecast if a business will fail or succeed within a stipulated period. Despite avoidance activities work in such a stochastic way, financial information generated can be used to develop or construct FCP - financial crisis prediction stereotype. For example, Christy and Arubkumar (2019) state applying the multiple variance piece of data approaches fundamentally, discriminant investigation for categorizing funds and bankrupt corporations by manipulating financial information. Financial distress does not only occurs due to insolvent as well as corrupting responsibility rankings of credit-based assets (Wang, Ma, and Yang, 2014). Despite circumvention practices being employed previously, financial crisis guide the operative financial crisis prediction with maximum importance (Cinca and Gutirrez-Nieto, 2013). On the other hand, Wang and his co-workers recommended that there are no typical stereotypes or theories occurs for a company's financial crisis predictions (Wang, Ma, and Yang, 2014). The non-existence of stereotypes or theories to analyze financial distress for fact-finding activities for the documentation of discriminant potentials and extrapolation replicas employing trial and error (Sun and $\mathrm{Li}$, 2012; Zhou, 2013; Vadlamudi, 2017).

Professionals and researchers have been working to improve the presentation of financial crisis prediction theoretical stereotypes by the application of different quantitative replica. For instance, Ohlson (1980) designed the most basic LR - logistic regression practice for circumvention calculation. Comparatively, many authors offer a grade to identify the opinion as both bad and good clients; Ohlson's stereotype calculates the typical probability of the major. Supposing the comparative comfort of executing discriminant scrutiny and LR, numerous research investigating the same tests has been completed. Moreover, Cinca and Gutirrez-Nieto (2013) came up with the suggestion that differs from the one provided by Altman (1968), Vadlamudi (2015), and Ohlson (1980), stereotypes are not accurate and suggested the necessity of enhancements in the exhibiting of avoidance risks.

As the search for a better model for predicting financial crisis continues, scholars discovered the machine learning (ML) and artificial intelligence (AI) methods to quantify financial crisis using modern and innovative technologies. Since the examination of credit risks is the same as the design identification issues, methods can be used for the sorting of the solvency, thus improving the orthodox approaches employing previously multiple variance statistical practices like LR and discriminant breakdown. The integration of machine learning algorithms with various forms of artificial neural networks in financial crisis prediction is of greater interest (Vadlamudi, 2016). However, this study focuses on the impact of machine learning in FCP and also introduce some important study in this aspect. Taking tangible duty as a case study in evaluating the impact of the theoretical financial crisis on productivity growth. 


\section{LITERATURE REVIEW}

\section{Machine learning Approaches}

\section{Design Arrangement}

The main purpose of the arrangement is to assign an unidentified case that is characterized by specific potential into one appropriate grade from a predictable set of ratings. The act of studying or learning consists of the compilation of a pattern or system by which approaching the representing amid inputoutcome patterns that allow the right classification of the learning set at a specific degree of precision (Ding, Song, and Zen, 2008). Immediately the pattern is developed or learned, it can be employed in sorting unidentified cases into one of the grade marks that are mug up in the studying category (1997).

Table 1: Class of Machine learning and Methods

\begin{tabular}{|c|c|c|}
\hline Class & Method & Literature \\
\hline \multirow[t]{5}{*}{$\begin{array}{l}\text { Controlled } \\
\text { learning }\end{array}$} & Decision trees & $\begin{array}{l}\text { Sung et al. (1999); } \\
\text { Bensic et al. (2005); Lee } \\
\text { et al. (2006); Yeh and } \\
\text { Lien, (2009) }\end{array}$ \\
\hline & $\begin{array}{l}\text { Support vector } \\
\text { machine (SVM) }\end{array}$ & $\begin{array}{l}\text { Shin et al. (2005); Min } \\
\text { and Yee (2005); Yang } \\
\text { (2007); Tsai (2008); } \\
\text { Martens et al. (2007) }\end{array}$ \\
\hline & $\begin{array}{l}\text { Neural network } \\
(\mathrm{NN})\end{array}$ & $\begin{array}{l}\text { Boritz and Kennedy } \\
\text { (1995), Lacher et al. } \\
\text { (1997); Leshno and } \\
\text { Spector (1996); Back et al. } \\
\text { (1996). }\end{array}$ \\
\hline & $\begin{array}{l}\text { Situation } \\
\text { oriented } \\
\text { Reasoning }\end{array}$ & $\begin{array}{l}\text { Lin et al. (2009); Cho et } \\
\text { al. (2010) }\end{array}$ \\
\hline & $\begin{array}{l}\text { k- next } \\
\text { neighbor }\end{array}$ & Boyacioglu et al. (2009) \\
\hline \multirow[t]{3}{*}{$\begin{array}{l}\text { Uncontrolled } \\
\text { learning }\end{array}$} & $\begin{array}{l}\text { Self-establishing } \\
\text { maps }\end{array}$ & $\begin{array}{l}\text { Boyacioglu et al. } \\
\text { (2009); Luo et al. (2009) }\end{array}$ \\
\hline & k-means & $\mathrm{Wu}(2010)$ \\
\hline & $\begin{array}{l}\text { Probability } \\
\text { intensification }\end{array}$ & $\begin{array}{l}\text { Boyacioglu et al. } \\
\text { (2009); Luo et al. (2009) }\end{array}$ \\
\hline \multirow{6}{*}{$\begin{array}{l}\text { Statistics- } \\
\text { oriented } \\
\text { learning }\end{array}$} & $\begin{array}{l}\text { Logistic } \\
\text { Regression }\end{array}$ & $\begin{array}{l}\text { Boyacioglu et al. (2009); } \\
\text { Chi and Tang (2006) }\end{array}$ \\
\hline & $\begin{array}{l}\text { Unexperienced } \\
\text { Bayers }\end{array}$ & Yeh and Lien (2009) \\
\hline & $\begin{array}{l}\text { Discriminant } \\
\text { investigation }\end{array}$ & Yeh and Lien (2009) \\
\hline & $\begin{array}{l}\text { Data wrapping } \\
\text { study }\end{array}$ & Min and Lee (2008) \\
\hline & $\begin{array}{l}\text { Isotonic } \\
\text { separation }\end{array}$ & Ryu and Yue (2005) \\
\hline & $\begin{array}{l}\text { Mahalanobis- } \\
\text { Taguchi }\end{array}$ & Lee (2007) \\
\hline \multirow[t]{4}{*}{$\begin{array}{l}\text { Other } \\
\text { methods }\end{array}$} & $\begin{array}{l}\text { Genetic } \\
\text { algorithms }\end{array}$ & Min and Jeong (2009) \\
\hline & $\begin{array}{l}\text { Group Technique } \\
\text { of Data } \\
\text { manipulation }\end{array}$ & $\begin{array}{l}\text { Ravisankar and Ravi } \\
\text { (2010) }\end{array}$ \\
\hline & Rough sats & Tay and Shen (2002) \\
\hline & Fuzzy sets & Min and Jeong (2009) \\
\hline
\end{tabular}

For examples of economic failure forecast and financial recording, the respective data model in the chosen dataset covers several fiscal proportions and equivalent binary grade ratings, on behalf of indebtedness or creditworthiness for liquidation forecast and bad/good credit for financial rating, accordingly. This allows the learning and analysis of the rater as an indebtedness-estimation pattern or financial rating pattern centered on a particular arrangement method (Lin et al., 2012).

\section{Single Sorting Methods}

In all-purpose, the issue to estimate credit risks can be the method by labeling a distinct classifier. Many pieces of research have been centered on a single sorting method with that indebtedness forecast and financial rating patterns can be developed (Lin et al., 2012). Some selected pieces of literature relating to designing FCP patterns that are centered on distinct classifiers are summarized in Table 1 . Thoroughly, these distinct sorting methods are classified into 4 classes, which are controlled learning, uncontrolled learning, statistics-oriented learning, and others methods. Additionally, these patterns are likened to distinct reference point patterns in terms of estimation presentation with which to attain a concluding assumption.

Furthermore, the proportional investigations of separate classifiers, a good number of researches have aimed at whether potential collection affecting the presentation of a particular distinct classifier (Liu and Schumann, 2005; Li et al., 2009; Li et al., 2010; Ravisankar and Ravi, 2010; Ravisankar, Ravi, and Bose, 2010; Sun and Li, 2008). All these pieces of literature established that given the choice of potentials to lower measurement endorses the presentation of a distinct classifier further than what is promising short of seeing potential choice. More so, several investigations short of potential choice used the original structures offered in the database, which are present for general view or chosen the potential based on the guidance of domain how-know.

\section{Soft Sorting Methods}

\section{Classifier Bands}

In model identification and ML, the blend of classifiers is now of great concern to a lot of investigators (Frosyniotis et al., 2003). The whole concept of mixing classifiers is stated by a probabilistic basis.

$p\left(\frac{t}{x}\right)=\sum_{k=1}^{k} w k p\left(\frac{t}{x 1 k}\right)$

where $\mathrm{p}(\mathrm{t} \mid \mathrm{x})=$ provisional dissemination specified by input variant $\mathrm{x}, \mathrm{k}=1,2, \ldots$,

$\mathrm{K}$ indexes a set of potential patterns,

$\mathrm{wk}=$ the probability for different patterns.

The above probabilistic basis was recommended to enhance the sorting presentation of distinct classifiers (Kittler et al., 1998). This blend is beneficial for errors produced by discrete classifiers on several portions of the input intergalactic. In this method, the presentation of integrated classifiers usually outpaces even the superlative distinct classifiers applied in segregation. Classifiers bands are centered on the divide-andconquer basis that a multipart issue is divided into a sub- 
issue that is making it a simpler task that is later solve employing a number of sorting methods. The solution obtained is then combined from the outcomes of the subtasks.

A good number of blend approaches have been adopted to combine classifier bands. The most modest approach is majority voting - here after the results of discrete classifiers are made, the class with the maximum figure of votes is chosen as the absolute classification choice. The remaining 2 characteristic approaches are boosting and bagging.

The bagging approach deals with many classifiers that are trained individually applying a good number of training sets through the bootstrap approaches (Brelman, 1996). For instance, ponder on an issue that we are attempting to forecast credit risks, that is centered on the input or feedback data $\mathrm{x}$. bootstrap datasets, $K$ can be generated by an unsystematic random sample with backup from the original drill information. At that time, we can use the individual bootstrap dataset to drill discrete forecast model $\mathrm{yk}(\mathrm{x})$ where $\mathrm{k}-1,2 \ldots \ldots . \mathrm{K}$. By so doing, individual training instance possibly will act repetitively but then again not at all in any specific working out dataset of $\mathrm{K}$. The concluding forecast of credit risks is presented by

$y(x)=1 / k \sum_{k=1}^{k} y k(x)$

This process has been widely scrutinized in this subject matter that is machine learning and the pieces of literature ascertained this approach as an effective way of combining multiple patterns. For example, the hypothetical breakdown according to Duda and his coworkers suggested the average error of a pattern can be lowered to $1 / \mathrm{K}$ by taking the average $\mathrm{K}$ type of the pattern (Duda et al., 2001).

Whereas in boosting, the $\mathrm{K}$ classifiers are trained not in an equivalent and autonomous manner, but then again chronologically. More particularly, individual fragile classifier yk $(\mathrm{x})$, where $\mathrm{k}=\mathrm{I}, 2 \ldots \ldots \mathrm{K}$, is trained by means of a biased form of original training statistics. In other words, individual data fact devising related weighting factor. At the different repetitions of the boosting algorithm, the weighting factor is in sync so that individual information fact devising a linked weighting constant. However, individual repetition of the boosting system, the weighting constants are manipulated so that the working out specimens that are wrongly sorted by recent weak classifier has a biased dataset. In the succeeding repetition, a new weak classifier is worked out through the restructured biased dataset. Due to this, the former wrongly sorted information facts will exert more effect in the working out of the next classifier. After K replications, a strong classifier can be obtained in the form below:

$y(x)=\operatorname{sign}\left(\sum_{k=1}^{k} \alpha k y k(x)\right)$

Where $\alpha \mathrm{k}$ equal to a biased degree of the sorting precision of the weak classifier $y k(x)$; or it can be stated that $\alpha \mathrm{k}$ apportions larger weight to a more precise weak classifier (Freund and Schapire, 1996).

\section{Hybrid Classifiers}

The notion of hybrid classifiers is centered on blending 2 or more varied machine learning methods. Usually, there are 3 methods of achieving this; i. Includes cascading diverse classifier - this process is the same as boosting, in which many classifiers are blended in a successive mode. Thus, cascaded hybrid classifiers are generally small, it does not take more than 2. More particularly, stage one of hybrid classifiers is worked out for a particular issue, and the outcome of this classifier becomes the feedback for stage two and others. Examples of cascading diverse classifiers include the neuro-fuzzy method (Jang et al., 1996; Malhotra and Malhotra, 2002), such that a neural connection pattern signifies the stage one classifier whose outcomes are applied as feedbacks to produce fuzzy guidelines in the stage two classifier as a fuzzy extrapolation structure.

ii. This second stage of classifiers deals with the workedout dataset $\mathrm{D}$ that contains $\mathrm{m}$ worked-out specimens that are applied to work out and analyze the stage one classifier. At that point, D is applied to work out the second stage classifier. According to Tsai and Chen (2010), stage two classifiers can offer excellent sorting outcomes than a distinct classifier worked out by the novel dataset $\mathrm{D}$ over a particular analysis established.

(a) Predicted credit-constrained status vs GF eligibility

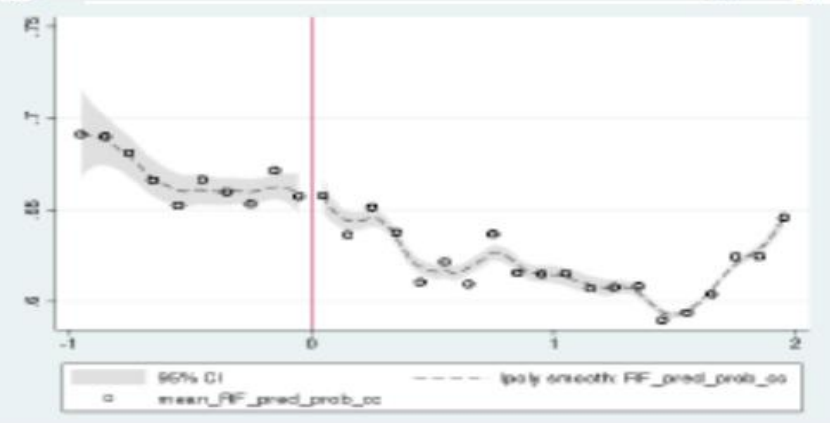

(b) Predicted creditworthy status vs GF eligibility

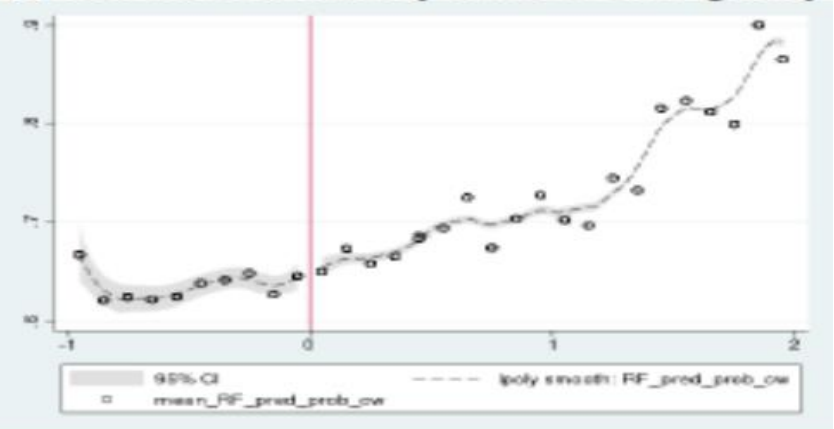

(c) Predicted MI target status vs GF eligibility

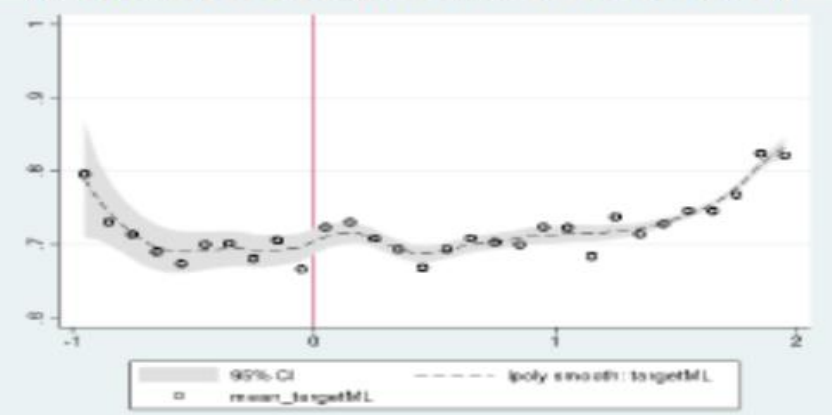

Figure 1: Possibility of being an ML-Targeted against Actual GF worthiness 


\section{Methods}

We select systematic literature assessment (SLA). This approach will help us to achieve our objective of this study which is the survey the impact of machine learning in the prediction of a financial crisis. The technique implemented in this study is the same as the method mentioned by Bhatnagar et al. (2020), Donepudi (2014), and Keele (2016).

\section{Study Problems}

To accomplish the above-stated study's aims, we considered 3 lead issues that would aid to report the objective of this paper by a thorough collection of works that make available responses to these problems. The problems are shown in Table 2 below.

Table 2: Study Problems (SPs)

1. What is the major impact address by machine learning in the financial institution?

2. What is the role of machine learning in the prediction of a financial crisis?

3. What methods are engaged by ML to tackle problems associated with the financial prediction?

\section{Selection of Relevant Literatures}

The literature used in this study was chosen according to the significance and relation with the objective of the study. For us to accomplish this we adapted the exploration method suggested by Dyba and Dingsoyr (2008) for the selection of significant literature that leads to a concrete inference. Also, literature with relevant keywords by the use of abstract was the second method used to choose appropriate literature based on Petersen et al. (2006) assumption. This was carried out in 2 phases. In the first one, we weighed the abstract to document the impact while the other phase was to study the keywords to determine the feature and importance of the literature. Consequently, ten relevant pieces of literature were carefully chosen for this study.

\section{Results AND Discussion}

The outcomes of this study are presented based on the study problems (SPs) specified in the method. Also, the study problems report questions that openly address the impact of machine learning in financial prediction if prudently follow.

SP1: What are the major impacts address by machine learning in the financial institution? And SP2: What is the role of machine learning in the prediction of the financial crisis?

The effects of machine learning in financial crisis predictions deal with major issues like bankruptcy or insolvency and credit securities. Andim et al. (2019) state the usefulness of ML as a predictive implement to recommend a strategy project rule constructed to improve the efficiency of public securities programs. Andim and co-workers address the public securities structure targeting organizations that are both creditworthy and financially constrained. This rule provided by machine learning can make available a standard to progress level to stretch the specified policy objectives. This literature investigates the case of Italy's guarantee fund (GF) by assessing if the machine learning-oriented targeting rule gives clues to an increase in the efficiency of the fund. Andim et al. (2019) study the impact of ML targeting in prediction by relying on two groups, based on whether they are targeted by machine learning or not.

At that point, they liken the average witnessed the performance of the 2 groups concerning a set of variables assessing together real and financial results for the fiscal year between 2011-15. The main purpose of this was to determine if the machine learning targeting the organization's group was more effective than the other group. This might help the decision-makers to increase the efficacy of the decision by merely eliminating a subcategory of the Fund's qualified organizations. This method is denoted as a contraction experiment according to Kleinberg et al. (2018). It is very direct, as it depends on a modest appraisal of experiential average results. According to Andim and co-workers, out of their selected samples of ninety thousand organizations, about seven thousand organizations received the GF in the fiscal year 2012 -2013. In the midst of them, approximately four thousand organizations that are about $60 \%$ were chosen as a target by the machine learning algorithms, while two thousand, eight hundred and sixty-nine beneficiaries were not chosen (see Table 3 and Figure $1 \mathrm{a}-1 \mathrm{c}$ ). In the middle of the latter, about $70 \%$ are rejected as a result of their non-machine learning predicted as credit-constrained organizations.

Table 3: Machine learning against beneficiaries organizations

\begin{tabular}{|c|c|c|c|}
\hline & \multicolumn{2}{|c|}{ ML target (B) } & \\
\hline GF beneficiary (A) & 0 & 1 & Total \\
\hline 0 & 15,165 & 66,426 & 81,591 \\
\hline 1 & 2.869 & 4,042 & 6,911 \\
\hline Total & 18,034 & 0,468 & 88,502 \\
\hline
\end{tabular}

(A): organizations that got the GF in the period 2012-13. (B): organizations predicted as target $(=1)$ or not $(=0)$ by the ML algorithm (random forest).

Other pieces of literature selected to address the first two study problems recommended machine learning as the principal means of addressing bankruptcy and creditworthiness and also, that ML targeted approach will help organizations like banks, government to advert the economic crisis if carefully follow (Lin et al., 2012; Christy and Arunkumar, 2019; Qu et al., 2019; Tiffin, A., 2019; Doerr et al., 2021). Also, Doerr et al. (2021) in their working paper presented early this year recommended machine learning is the best method in managing big data which might very difficult to supervise and regulate with any other approach. They iterated the big issue of data quality, representatives, and sampling which are the major challenges in the central banks all together with uncertainty associated with confidentiality and data privacy can now be addressed by incorporating machine learning algorithm in the financial institutions.

SP3: What methods are engaged by ML to tackle problems associated with the financial prediction?

According to Qu et al. (2019), the recent evolvement in the IT world via machine learning approach has brought a deep learning approach to address financial crisis prediction by using the right algorithms to address insolvency forecast, as well as the standard machine learning patterns such as Logistic Regression (LR), Multiple-variance Discriminant Analysis (MDA), Neural Networks (NN), Ensemble method, 
and Support Vector Machines (SVM), and foremost profound learning approaches mentioned in Table 1. All the literature selected to answer this study problem emphasizes the importance of ML-oriented algorithms in addressing financial crisis prediction.

\section{Conclusion And Recommendation}

Conventionally, financial crisis prediction has been a major challenge in the financial world. Although most of the literature might be referred to it as a passive observation that might affect the output. Also, available studies described machine learning as a typical tool for prediction but currently concentrating on the crisis and risk prompting in part by growing to understand that numerous complications originate from (Donepudi, 2019). Considering the prices of a financial crisis as a demonstrative pattern, the study has tried to show how such methods can yield reasonable effects-the predictable average effect of a crisis, for case in point. It is dependable with preceding predictions, as is the likely role for exchange-rate plasticity or financial growth in determining the cost for any specific country.

Additionally, ML can also permit for a meaningfully better-off conversation of possible beginnings and non-linearity; to a degree that is typically not possible applying more outdated econometric approaches. In general, by allowing the deliberation of an opulent set of variables and connections, and permitting for a more custom-made valuation of the separate conditions of each country. ML can offer a priceless accompaniment to the performances presently used by economists, both within the Fund and outside.

\section{REFERENCES}

Andini, M., Boldrini, M., Ciani, E., de Blasio, G., D'Ignazio, A. and Paladini, A. (2019). Machine learning in the service of policy targeting: the case of public credit guarantees. Temi di discussion (working paper), 1-88.

Back, B., Laitinen, T. and Sere, K. (1996). Neural networks and genetic algorithms for bankruptcy predictions. Expert Syst. Appl., 11, 407-413.

Bensic, M., Sarlija, N. and Zekic-Susac, M. (2005). Modelling smallbusiness credit scoring by using logistic regression, neural networks and decision trees. Intell. Syst. Account., Finance Manag, 13, 133-150.

Bhatnagar, V., Singh, G., Kumar, G. and Gupta, R. (2020). Internet of Things in Smart Agriculture: Applications and Open Challenges. International Journal of Students' Research in Technology \& Management, 8(1): 11-17.

Boritz, J. E. and Kennedy, D. B. (1995). Effectiveness of neural network types for prediction of business failure. Expert Syst. Appl., 9, 503-512.

Boyacioglu, M.A., Kara, Y. and Baykan, O. K. (2009). Predicting bank financial failures using neural networks, support vector machines and multivariate statistical methods: A comparative analysis in the sample of savings deposit insurance fund (SDIF) transferred banks in Turkey. Expert Syst. Appl., 36, 3355-3366.

Breiman, L. (1996). Bagging predictors. Machine Learning, 24(2): 123-140.

Chi, L. C. and Tang, T. C. (2006). Bankruptcy prediction: Application of logit analysis in export credit risks. Australian J. Manag., 31(1):17-28.
Cho, S., Hong, H. and Ha, B.C. (2010). A hybrid approach based on the combination of variable selection using decision trees and case-based reasoning using the Mahalanobis distance: For bankruptcy prediction. Expert Syst. Appl., 37, 3482-3488.

Christy, S.A. and Arunkumar, R. (2019). Machine Learning Based Classification Models for Financial Crisis Prediction. International Journal of Recent Technology and Engineering (IJRTE) ISSN: 2277-3878, 8(4): 4887-4893.

Cinca, S. and Gutirrez-Nieto, B. (2013). Partial least square discriminant analysis for bankruptcy prediction, Decis. Support Syst., 54(3): 1245-1255.

Ding, Y., Song, X. and Zen, Y. (2008). Forecasting financial condition of Chinese listed companies based on support vector machine. Expert Syst. Appl., 34, 3081-3089.

Doerr, S., Gambacorta, L. and Serena, J. M. (2021). Big data and machine learning in central banking. BIS Working Papers, March 2021. 930, 1-26.

Donepudi, P. K. (2019). Automation and Machine Learning in Transforming the Financial Industry. Asian Business Review, 9(3), 129-138. https://doi.org/10.18034/abr.v9i3.494

Donepudi, P. K. (2014). Technology Growth in Shipping Industry: An Overview. American Journal of Trade and Policy, 1(3), 137-142. https://doi.org/10.18034/aitp.v1i3.503

Duda, R. O., Hart, P. E. and Stork, D. G. (2001). Pattern Classification, 2nd ed. New York: Wiley.

Dybå, T., Dingsøyr, T. (2008). Empirical studies of agile software development: A systematic review. Inf. Softw. Technol., 50, 833-859.

Freund, Y. and Schapire, R. E. (1996). Experiments with a new boosting algorithm. In Proc. Int. Conf. Mach. Learning, Bari, Italy, pp. 148- 156.

Frosyniotis, D., Stafylopatis, A. and Likas, A. (2003). A divide-andconquer method for multi-net classifiers. J. Pattern Analysis Appl., (6)1, pp. 32-40.

Jang, J. S., Sun, C. T. and Mizutani, E. (1996). Neuro-Fuzzy and Soft Computing: A Computational Approach to Learning and Machine Intelligence, NJ: Prentice-Hall.

Keele, S. (2016). Guidelines for Performing Systematic Literature Reviews in Software Engineering; Technical Report 2016, Ver. 2.3 Technical Report; EBSE: Durham, UK.

Kittler, J., Hatef, M., Duin, R. P. W. and Matas, J. (1998). On combining classifiers. IEEE Trans. Pattern Anal. Mach. Intell., 20(3): 226- 239 .

Kleinberg, J., Ludwig, J., Mullainathan, S., and Obermeyer, Z. (2015). Prediction policy problems. American Economic Review, 105(5): 491-495.

Lacher, R. C., Coats, P. K., Sharma, S. C. and Fant, L. F. (1995). A neural network for classifying the financial health of a firm. Eur. J. Oper. Res., 85, 53-65.

Lee, T. S., Chiu, C. C., Chou, Y. C. and Lu, C. J. (2006). Mining the customer credit using classification and regression tree and multivariate adaptive regression splines. Comput. Statist. Data Anal., 50, 1113-1130.

Lee, Y. C. (2007). Application of support vector machines to corporate credit rating prediction. Expert Syst. Appl., 33, 67-74.

Leshno, M. and Spector, Y. (1996). Neural network prediction analysis: The bankruptcy case. Neurocomputing, 10, 125-147.

Li, H., Huang, H. B., Sun, J. and Lin, C. (2010). On sensitivity of casebased reasoning to optimal feature selection subsets in business failure prediction. Expert Syst. Appl., 37, 4811-4821. 
Lin, R. H., Wang, Y. T., Wu, C. H., and Chung, C. L. (2009). Developing a business failure prediction model via RST, GRA and CBR. Expert Syst. Appl., 36, 1593-1600.

Lin, W. Y., Hu, Y. H and Tsai, C. F. (2012). Machine Learning in Financial Crisis Prediction: A Survey. IEEE Transactions on Systems, Man, and Cybernetics, Part C (Applications and Reviews). 42(4), 421-436. https:/ / doi.org/10.1109/tsmcc.2011.2170420

Lin, W. Y., Hu, Y. H and Tsai, C. F. (2012). Machine Learning in Financial Crisis Prediction: A Survey. IEEE Transactions on Systems, Man, and Cybernetics - Part C: Applications and Reviews, 42(4): 421-436.

Liu, Y. and Schumann, M. (2005). Data mining feature selection for credit scoring models. J. Oper. Res. Soc., 56(9):1099-1108.

Luo, S. T., Cheng, B. W. and Hsieh, C. H. (2009). Prediction model building with clustering-launched classification and support vector machines in credit scoring. Expert Syst. Appl., 36, 7562-7566.

Malhotra, R., and Malhotra, D. K. (2002). Differentiating between good credits and bad credits using neuro-fuzzy systems. Eur. J. Oper. Res., 136, 190-211.

Martens, D., Baesens, B., VanGestel, T. and Vanthienen, J. (2007). Comprehensible credit scoring models using rule extraction from support vector machines. Eur. J. Oper. Res., 183(3): 1466-1476.

Min J. H. and Jeong, C. (2009). A binary classification method for bankruptcy prediction. Expert Syst. Appl., 36, 5256-5263.

Min J. H. and Lee, Y. C. (2008). A practical approach to credit scoring. Expert Syst. Appl., 35, 1762-1770.

Min, J. H. and Lee, Y. C. (2005). Bankruptcy prediction using support vector machine with optimal choice of kernel function parameters. Expert Syst. Appl., 28, 603-614.

Ohlson, J. A. (1980). Financial ratios and the probabilistic prediction of bankruptcy. J. Account. Res., 18(1): 109-131.

Petersen, K., Feldt, R., Mujtaba, S. and Mattsson, M. (2006). Systematic mapping studies in software engineering. In Proceedings of the 12th International Conference on Evaluation and Assessment in Software Engineering (EASE), Bari, Italy, 8, 68-77.

Ravisankar P. and Ravi, V. (2010). Financial distress prediction in banks using Group Method of Data Handling neural network, counter propagation neural network and fuzzy ARTMAP. Know.-Based Syst., 23, 823-831.

Ravisankar, P., Ravi, V. and Bose, I. (2010). Failure prediction of dotcom companies using neural network-genetic programming hybrids. Inf. Sci., 180, 1257-1267.

Ryu Y.U. and Yue, W.T. 2005. Firm bankruptcy prediction: Experimental comparison of isotonic separation and other classification approaches. IEEE Trans. Syst., Man, Cybern. A, Syst. Humans, 35(5): 727-737.
Shin, K. S., Lee, T. S. and Kim, H. J. (2005). An application of support vector machines in bankruptcy prediction model. Expert Syst. Appl., 28, 127-135.

Sun, J. and Li, H. (2012). Financial distress prediction using support vector machines: Ensemble vs. Individual. Appl. Soft Comput. 12(8): 2254-2265.

Sun, J. and Li, H. (2008). Data mining method for listed companies' financial distress prediction. Know-Based Syst., 21, 1-5.

Sung, T. K., Chang, N. and Lee, G. (1999). Dynamics of modeling in data mining: Interpretive approach to bankruptcy prediction. J. Manag. Inf. Syst., 16(1): 63-85.

Tay F. E. H. and Shen, L. (2002). Economic and financial prediction using rough sets model. Eur. J. Oper. Res., 141, 641-659.

Tiffin, A. (2019). Machine Learning and Causality: The Impact of Financial Crises on Growth. IMF Working Paper, November 2019, pp. 1-31.

Tsai, C. F. (2008). Financial decision support using Neural Networks and support vector machines. Expert Syst., 25(4): 380-393, 2008.

Tsai, C. F. and Chen, M. L. (2010). Credit rating by hybrid machine learning techniques. Appl. Soft Comput., 10, 374-380.

Vadlamudi, S. (2015). Enabling Trustworthiness in Artificial Intelligence - A Detailed Discussion. Engineering International, 3(2), https://doi.org/10.18034/ei.v3i2.519

Vadlamudi, S. (2016). What Impact does Internet of Things have on Project Management in Project based Firms?. Asian Business Review, 6(3), 179-186. https://doi.org/10.18034/abr.v6i3.520

Vadlamudi, S. (2017). Stock Market Prediction using Machine Learning: A Systematic Literature Review. American Journal of Trade and Policy, 4(3), 123-128. https://doi.org/10.18034/ajtp.v4i3.521

Wang, G., Ma, J. and Yang, S. (2014). An improved boosting based on feature selection for corporate bankruptcy prediction. Expert Syst. Appl., 41(3): 2353-2361.

Wu, W. W. (2010). Beyond business failure prediction. Expert Syst. Appl., 37, 2371-2376.

Yang, Y. (2007). Adaptive credit scoring with kernel learning methods. Eur. J. Oper. Res., 183, 1521-1535.

Yeh I. C. and Lien, C. H. (2009). The comparisons of data mining techniques for the predictive accuracy of probability of default of credit card clients. Expert Syst. Appl., 36, 2473-2480.

Zhou, L. (2013). Knowledge-Based Systems Performance of corporate bankruptcy prediction models on imbalanced dataset: The effect of sampling methods, 41, 16-25.

$--0--$

\section{How to cite this article}

Vadlamudi, S. (2020). The Impacts of Machine Learning in Financial Crisis Prediction. Asian Business Review, 10(3), 171-176. https://doi.org/10.18034/abr.v10i3.528 